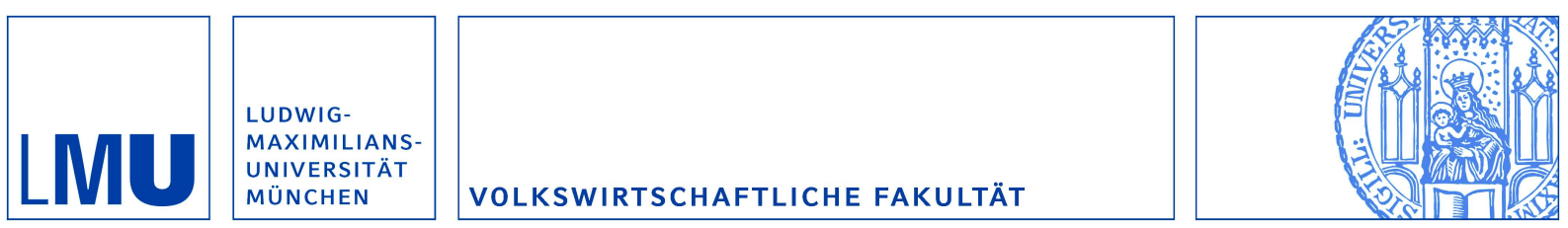

Ortalo-Magné, François und Rady, Sven:

Heterogeneity within Communities: A Stochastic Model with Tenure Choice

Munich Discussion Paper No. 2005-8

Department of Economics

University of Munich

Volkswirtschaftliche Fakultät

Ludwig-Maximilians-Universität München

Online at https://doi.org/10.5282/ubm/epub.594 


\title{
Heterogeneity Within Communities: A Stochastic Model with Tenure Choice*
}

\author{
François Ortalo-Magné ${ }^{\dagger}$ \\ University of Wisconsin-Madison
}

\author{
Sven Rady \\ University of Munich
}

\begin{abstract}
Standard explanations for the income heterogeneity within neighborhoods rely on differences of preferences across households and heterogeneity of the housing stock. We propose an alternative and complementary explanation. We construct a stochastic equilibrium sorting model where (1) income is the sole dimension of household heterogeneity, (2) households form state-contingent housing location plans that may involve moves over their lifetimes, (3) households choose whether to own or rent depending on the housing expenditure risk associated with each tenure mode, and (4) there is a probability that newcomer households move in and compete for homes with native households. Income mixing within neighborhood arises for two reasons. First, allowing natives to form state-contingent housing location plans breaks the indivisibility of housing consumption implicit in the literature where households choose their location once and for all. Second, natives can insure themselves against rent fluctuations by buying their home prior to the realization of the population shock; newcomers cannot. As a result, poorer natives stay in the more desirable communities and only richer newcomers move in these communities. Evidence from U.S. metropolitan areas supports the effects predicted by the model.
\end{abstract}

\footnotetext{
*We are grateful to Yannis Ioannides for providing the AHS neighborhood cluster sample data. Our thanks for helpful comments and discussions are due to Steven Durlauf, Erzo G.J. Luttmer and Holger Sieg. The hospitality and support of the Lincoln Institute of Land Policy and the Center for Economic Studies at the University of Munich are gratefully acknowledged.

${ }^{\dagger}$ Department of Real Estate and Urban Land Economics, University of Wisconsin-Madison, 975 University Avenue, Madison, WI 53706; email: fom@bus.wisc.edu.

${ }^{\ddagger}$ Department of Economics, University of Munich, Kaulbachstr. 45, D-80539 Munich, Germany; email: sven.rady@lrz.uni-muenchen.de.
} 


\section{Introduction}

There is considerable income heterogeneity within neighborhoods. Epple and Sieg (1999) tell us that in 1980, 89 percent of the income variance in the Boston metropolitan area could be explained by within-community variance. Ioannides (2004) finds a correlation coefficient of only 0.3 between the income of a randomly chosen individual and that person's ten nearest neighbors. Hardman and Ioannides (2004) discover that in 1993 more than two-thirds of U.S. metropolitan neighborhoods in the American Housing Survey included at least one household with income in the bottom quintile of the metropolitan income distribution; more than half the neighborhoods had at least one household with income in the top quintile.

The empirical evidence is at odds with the prediction of early equilibrium sorting models that assume households differ according to income only; examples are Ellickson (1971) and Henderson (1991). These models predict that a community will consist of households whose incomes lie in a single interval and the set of communities partitions the support of the income distribution.

A number of models that address this discrepancy between theory and evidence presume households differ not only in terms of income but also in terms of preferences; see Epple and Platt (1998) and Epple and Sieg (1999). The equilibrium sorting models that include these two dimensions of household heterogeneity still predict that household incomes within a community lie in one single interval, but intervals may overlap because households with the same level of income can value the amenities offered by a community differently.

We propose an alternative explanation for the income heterogeneity within neighborhoods. In our equilibrium sorting model, income is the sole dimension of household heterogeneity, yet the equilibrium distribution of households across communities is not stratified according to income. There are pairs of households where the higher earning household lives in the cheaper community.

We obtain this prediction because we pose the community choice problem within a dynamic and stochastic environment where the cost of each location is determined in equilibrium. Three primary features of the model are that: (1) households form state-contingent housing location plans that may involve moves over their lifetimes, (2) households choose whether to own or rent a home on the basis of aversion to housing expenditure risk, (3) there is a probability that new households move into the area and compete for homes with the current inhabitants. 
We construct a two-period model of a city with two communities. Households are assumed to be risk averse. They all derive the same utility from living in the more desirable of the two communities. Housing in this community is available in a fixed supply and can be either rented or purchased from competitive risk-neutral absentee landlords. For simplicity, we assume the supply of housing in the less desirable community to be perfectly elastic. In the second period, there is a positive probability that some newcomers move to the city. They enjoy the same utility from numeraire and location as the current residents (natives). Like the natives, they differ in income levels.

Income mixing arises for two reasons. First, allowing native households to make statecontingent location plans breaks the indivisibility of housing consumption implicit in the literature where households choose their location once and for all. Consider two households with different incomes living in different neighborhoods. The lower earning household may be living in a nicer neighborhood because it plans to move to a cheaper neighborhood in the future, while the higher earning household may have decided to live in its neighborhood for life.

Second, natives who want to remain in a neighborhood no matter what happens to local rents have a chance to insure themselves against future rent fluctuations by buying a home prior to the realization of the shock. Newcomers do not. Natives and newcomers thus have different housing opportunities, which affects the income distribution within neighborhoods. In response to the arrival of newcomers, fewer natives move out of the desirable community because they benefit from capital gains on their home when the cost of housing increases. As a result, the income distribution of the newcomers who choose that same community is truncated at a higher level. The natives who stay in the desirable community are poorer; the newcomers who come in are richer than in a rental-only economy.

We use data from the cluster component of the American Housing Survey to investigate relationships between the income of a household and its neighbors and the time since a household and its neighbors moved into the neighborhood. Households that moved in later than their neighbors are found to have higher incomes. This relationship disappears when we consider the sub-sample of renters. It holds in the sub-sample of owners even when we control for the value of a household's home relative to that of its neighbors. We also find a more dispersed distribution of income within a neighborhood, the greater the differences in the timing of households' moves into the neighborhood.

Ioannides (2004) studies the income distribution of neighborhood clusters using the same data from the American Housing Survey. He reports that the coefficient of variation 
in neighborhood incomes increases with the mean time since a household moved into the neighborhood. He also finds that neighborhoods of renters are less heterogeneous than neighborhoods of owners, another fact that indicates the relevance of the forces we identify in our model.

Gyourko, Mayer and Sinai (2004) study the differences in income between natives and newcomers across census-designated places within US metropolitan areas. They find that newcomers tend to be richer than natives in neighborhoods that have experienced price growth. Neighborhoods with the highest price growth attract a disproportionate share of the rich households moving to the metropolitan area. This finding supports the prediction of our model that variations in the times households move into a neighborhood contribute to income mixing within neighborhoods.

Davidoff (2004) finds that considerable income mixing remains even when one corrects for income reporting errors and for discrepancies between current and permanent income. That income heterogeneity is not due simply to discrepancies between current and permanent income is reinforced by a finding that household education levels are as heterogeneous within neighborhoods as income levels (Ioannides, 2004).

A possible explanation of income mixing within neighborhoods is that housing is heterogeneous. Keely (2004) explains why developers have incentives to develop subdivisions with heterogeneous homes. Nechyba (2000) presents a computational model with heterogeneous housing stock within communities in order to analyze private school voucher policies. We obtain our results without assuming any heterogeneity in the stock of homes in a location. Although heterogeneity of the housing stock must play a role in shaping the income distribution of a neighborhood, we note that Ioannides (2004) finds that both household income and education levels are more heterogeneous than property values.

Bénabou (1996a, 1996b), Durlauf (1996) and Fernandez and Rogerson (1996, 1998) propose dynamic sorting models to analyze macroeconomic and policy issues. They assume that the benefits of living in a community depend on the make-up of the community. They are therefore determined endogenously. The same is true in static models that determine the benefits of each community by a political equilibrium; see, for example, Epple and Sieg (1999). Common to these models is that households make only one location decision in equilibrium, either by assumption or because of a focus on stationary environments. We instead take the amenities of a community as given, but we allow households to relocate and to choose whether to own or rent their property in the face of endogenous fluctuations in housing costs. 
Berglas and Pines (1981) obtain income mixing in a model where local jurisdictions provide more than one public good. In Berglas (1976), Stiglitz (1983), McGuire (1981) and Brueckner (1994), income mixing arises because firms have a production technology which requires the use of low and high-skilled workers and workers must live in the same jurisdiction as they work. In a monocentric model of a city with distinct center city and suburban jurisdictions, de Bartolome and Ross (2003) obtain heterogeneity within jurisdictions. However, households are perfectly stratified according to income over space within each jurisdiction. The mechanisms that generate income mixing in these papers are entirely different from the ones we model.

Although our discussion is cast in terms of communities within the same urban area, our arguments apply equally to cities within a region. Our differentiating factor is the combination of a city's elasticity of housing supply and its desirability. This is a useful interpretation because Gyourko, Mayer and Sinai (2004) indicate that households that move to desirable cities with inelastic housing supplies tend to be richer than the households already living in these cities.

\section{Model}

To analyze the location choices of households in an environment where they may move in response to shocks we need a model with at least two locations and two periods. To analyze the housing market interaction between current (native) households and newcomers, we assume that newcomers may appear in the second period. This population shock affects equilibrium housing rents and prices.

As in Ortalo-Magné and Rady (2002), we focus on tenure choice driven by concerns over future housing expenditure risk. Davidoff (2003), Diaz-Serrano (2004), Han (2004) and Hilber (2005) provide evidence of the relevance of this driver of tenure choice. The two-period model captures the idea that, at short horizons, household concerns over period-to-period rent risk are dominated by concerns over end-of-holding-period price risk, and vice versa at long horizons. Empirical support for this idea is provided in Sinai and Souleles (forthcoming). From a modeling standpoint, the innovation in the present paper is that we cast such tenure concerns within an equilibrium model of the housing market. 


\subsection{Economic environment}

There are two periods, 1 and 2 , and two communities, 0 and 1 . In community 0 , the supply of homes is perfectly elastic at a constant rent normalized to zero. In community 1 , there is a measure $S$ of identical homes owned initially by absentee landlords. For simplicity, the landlords are assumed to be risk-neutral. They discount rents at the same exogenous interest rate, $r>0$, at which households can borrow and save.

Initially, the area is populated by a measure one of households, that we call the natives. They are distributed uniformly over the unit interval. Each one is identified by an index $i \in[0,1]$. Household $i$ receives a stream of income defined by $w_{1}(i)$ in period 1 , and $w_{2}(i)$ in period 2 , both increasing continuous functions of $i$. The capitalized value of the endowment of household $i$ evaluated in period 2 is denoted $W(i)$, with $W(i)=$ $(1+r) w_{1}(i)+w_{2}(i)$.

Native households derive additively separable utility from the consumption of housing and the numeraire good. Community 1 is more desirable than community 0: housing utility derived from a home in community 0 is normalized to zero, whereas a home in community 1 yields an additive utility premium of $\mu>0$ per period, whether the home is owned or rented. There is no discounting of utility across periods. The numeraire good is enjoyed at the end of period 2 only. The utility derived from consumption of $c$ units of the numeraire good is described by the constant absolute risk aversion function $U(c)=-e^{-a c}$ where $a>0$ is the coefficient of absolute risk aversion.

There is uncertainty in period 2. With probability $\pi \in(0,1)$, state $H$ occurs: A measure $\nu$ of newcomer households moves to the area at the start of period 2. With probability $1-\pi$, state $L$ occurs: Nobody moves in. Although the shock is asymmetric by design, we will see later that from the point of view of the natives, it amounts to either a rent increase (state $H$ ), or a rent decline (state $L$ ). Our specific modeling choice for the shock is motivated by our interest in the allocation of homes between households that had a chance to buy their homes early and those who move in later.

Newcomers are distributed uniformly over the unit interval; they are characterized by the index $n \in[0,1]$. Their endowment is defined by the increasing and continuous function $\tilde{W}(n)$. Newcomers have the same utility function as natives except that they cannot obtain any utility from housing in period 1 . The only decision they face is whether to live in community 0 or 1 if state $H$ occurs and how much of the numeraire good to consume. 
Within each period, households first receive their endowments. Then, the markets open and trade takes place. Next, households consume housing and, in period 2, the numeraire good.

For ease of exposition, we assume $0<\nu<S<\frac{1}{2}$ throughout. These assumptions limit the number of cases we will have to consider without taking anything away from the results.

\subsection{Tenure choice}

Whether a household owns or rents a home in community 0 , the cost is nil by assumption. Since we also assume that housing utility does not depend on tenure, all households are indifferent between renting and owning a home in community 0 .

Tenure matters for homes in community 1 . We denote $R_{1}$ their rent in period $1 ; R_{H}$ in period 2 , state $H$; and $R_{L}$ in period 2, state $L$. We first assume $R_{L}<R_{H}$. We will see later that this inequality must hold in any equilibrium where some newcomers choose community 1 in state $H$.

Arbitrage on the part of the landlords ensures that the price of a home in period 1 , $p_{1}$, equals the first-period rent plus discounted expected second-period rent:

$$
p_{1}=R_{1}+\frac{\bar{R}_{2}}{1+r}
$$

where $R_{1}$ denotes the first-period rent and $\bar{R}_{2}=\pi R_{H}+(1-\pi) R_{L}$ the expected secondperiod rent. Since period 2 is the last period of the economy, renting a home in period 2 is equivalent to buying it, so the price of a home in period 2 coincides with the rental cost of that home in period 2 .

Equation (1) describes the meaning of ownership in the model. By purchasing a home in the first period, a household effectively signs a two-period rental contract, locking in the second-period rent at its expected level. Whether buying is more or less risky than renting depends on the household's planned housing consumption in the second period. If the household plans to stay in community 1 in the second period, buying provides insurance against second-period rent risk. If the household plans to sell and move to community 0 in period 2, buying exposes it to potential capital gains or losses; renting eliminates this risk.

Further notation describes location and tenure choices. A native household's location plan is denoted by $\left(h_{1}, h_{H}, h_{L}\right)$, where $h_{1}, h_{H}$ and $h_{L}$ take the value of 1 for community 1 , 
and 0 for community 0 . To indicate the tenure choice when $h_{1}=1$, we denote the combined location-tenure plan by $\left(1_{B}, h_{H}, h_{L}\right)$ if the household buys a home, and $\left(1_{R}, h_{H}, h_{L}\right)$ if it rents one. Figure 1 summarizes the location-tenure choices available to a native household.

PERIOD 1

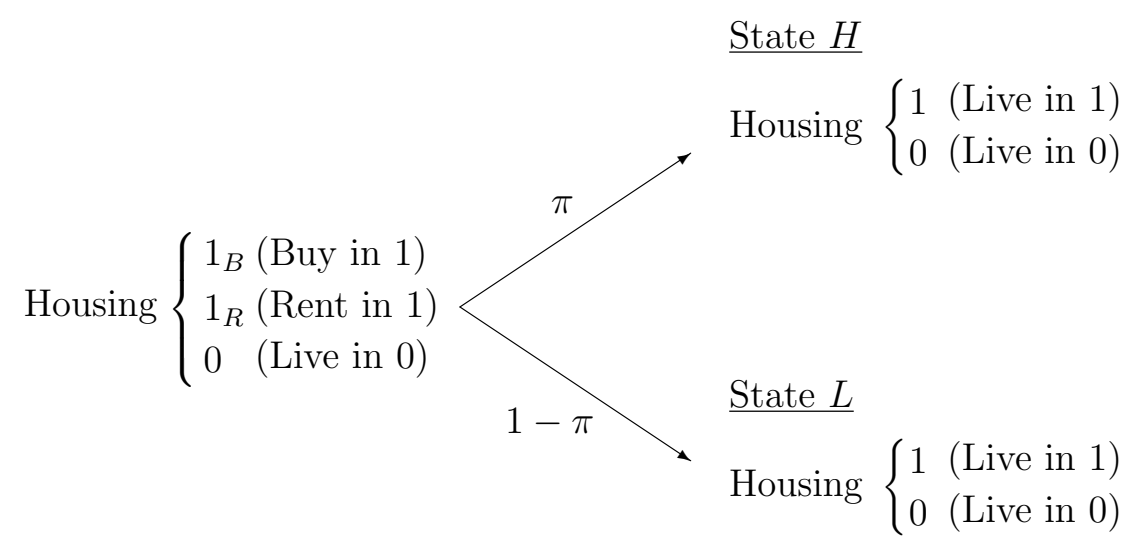

Figure 1: Native households' housing choices

Natives choose among twelve location-tenure plans. There are eight location plans. There are two alternatives for each of period 1 , period 2 , state $H$, and period 2 , state $L$. For the four location plans that involve living in location 1 in period 1 , native households must decide whether to buy or rent.

The tenure choice affects how shocks to the housing markets translate into shocks to the household's cost of housing and then through the budget constraint into shocks to non-housing consumption. The stochastic properties of numeraire consumption are therefore what is at issue with regard to the choice of tenure.

For example, consider the expected numeraire consumption of a household that chooses to live in location 1 in period 1 and in period 2, whatever the shock. If the household rents in period 1, it pays first-period rent and then realized rent in period 2. Its expected numeraire consumption is

$$
\pi\left(W-R_{1}-R_{H}\right)+(1-\pi)\left(W-R_{1}-R_{L}\right) .
$$


If the household buys in period 1, it pays first-period rent and expected second-period rent. Its expected numeraire consumption is

$$
\pi\left(W-R_{1}-\bar{R}_{2}\right)+(1-\pi)\left(W-R_{1}-\bar{R}_{2}\right) .
$$

By equation (1), both expressions simplify to the same amount of expected numeraire consumption, $W-R_{1}-\bar{R}_{2}$. That is, expected numeraire consumption is independent of tenure choice. The same holds for every other plan that involves a tenure choice.

Because households are risk-averse, this property of expected numeraire consumption implies that the tenure decision reduces to choosing the option that produces the smallest absolute difference between the numeraire consumption levels in the two states of the economy.

For the location plans with a deterministic horizon in the type 1 home, $(1,0,0)$ and $(1,1,1)$, the tenure choice is obvious as one of the tenure modes provides full insurance and the other does not. A household that rents in period 1 and moves to location 0 in period 2 does not suffer any shock to its consumption of numeraire. A household that buys in period 1 and remains in location 1 in period 2 does not face any numeraire consumption risk either. The location-tenure plans $\left(1_{R}, 0,0\right)$ and $\left(1_{B}, 1,1\right)$ therefore dominate the plans $\left(1_{B}, 0,0\right)$ and $\left(1_{R}, 1,1\right)$, respectively.

Under the location plans $(1,1,0)$ and $(1,0,1)$, however, either tenure mode imposes some risk on the household. Under $(1,1,0)$, if the household rents, it pays the rent $R_{H}$ in state $H$ and no rent in state $L$; its numeraire consumption is lower by $R_{H}$ in state $H$ than in state $L$. If the household buys in the first period, it sells the home if the state $L$ occurs. The price of a location 1 home in state $L$ is $R_{L}$. The household's numeraire consumption is therefore lower by $R_{L}$ in state $H$ than in state $L$ if it buys in period 1 . Buying is thus less risky, given our working assumption that $R_{L}$ is lower than $R_{H}$. The household that buys faces less risk in terms of second-period numeraire consumption. The location-tenure plan $\left(1_{B}, 1,0\right)$ therefore dominates the plan $\left(1_{R}, 1,0\right)$.

Under $(1,0,1)$, the logic is reversed. If the household rents in the first period, numeraire consumption in state $L$ is lower by $R_{L}$ since the second-period rent is paid only in state $L$. If the household buys the home in the first period, numeraire consumption in state $H$ is higher by $R_{H}$ since the household sells its home in state $H$. Buying involves a greater difference in realized numeraire consumption. The location-tenure plan $\left(1_{R}, 0,1\right)$ therefore dominates the plan $\left(1_{B}, 0,1\right)$.

We summarize these findings in 
Lemma 1 If $R_{L}<R_{H}$, a native household wanting to live in location 1 in the first period prefers to own its home if and only if it plans to stay in location 1 should state $H$ occur in the second period.

\subsection{Community choice}

¿From the twelve location-tenure plans we started with, we have shown that four are dominated. We are left with eight plans to consider: $(0,0,0),(0,0,1),(0,1,0),(0,1,1)$, $\left(1_{R}, 0,0\right),\left(1_{R}, 0,1\right),\left(1_{B}, 1,0\right)$, and $\left(1_{B}, 1,1\right)$. Each of these plans determines a curve in the plane with coordinates $W$ (the household's capitalized endowment) and $E U$ (the expected overall utility level). Determining the optimal plan for every $W$ amounts to characterizing the upper envelope of the expected utility curves. In the discussion, we maintain our working assumption that $R_{L}<R_{H}$.

First, the CARA specification of non-housing utility implies that the expected utility of any location-tenure plan can be written as $E U=-A e^{-a W}+B$ with plan-specific constants $A>0$ and $B \geq 0$, where $B \in\{0, \pi \mu,(1-\pi) \mu, \mu,(1+\pi) \mu,(2-\pi) \mu, 2 \mu\}$ is the expected utility of housing. For example, for the plan $\left(1_{B}, 1,1\right)$, the expected utility takes the form

$$
E U_{\left(1_{B}, 1,1\right)}=-e^{a\left[(1+r) R_{1}+\bar{R}_{2}\right]} e^{-a W}+2 \mu .
$$

It is easy to check that if the expected utility curves of two plans cross, the curve associated with the plan that promises a longer expected time in community 1 (and so has the higher $B$ ) is steeper at all endowment levels (greater $A$ ). Note also that the higher $B$, the greater the expected utility as $W$ increases (the limit of $E U$ as $W$ tends to infinity is $B$ ). This immediately yields

Lemma 2 The amount of housing a native household expects to consume in community 1 is increases weakly with the household's endowment.

Second, using CARA utility, it is easy to verify that the preference ranking of the plans $\left(1_{R}, 0,0\right)$ and $(0,1,1)$ does not depend on the household's endowment $W$. In other words, the expected utility curves associated with these two plans are either identical or do not intersect. Both plans generate the same utility of housing, $\mu$; their ranking is thus determined by the cost difference alone.

Lemma 3 The plan $\left(1_{R}, 0,0\right)$ weakly dominates $(0,1,1)$ if and only if

$$
e^{a(1+r) R_{1}} \leq \pi e^{a R_{H}}+(1-\pi) e^{a R_{L}},
$$


with a strict preference if the inequality is strict.

Third, building on what we have learned so far about household tenure and location decisions, we find that the plans $(0,1,0)$ and $\left(1_{B}, 1,0\right)$ are not chosen by anyone when $R_{L}<R_{H}$. Increasing the wealth of a household that chooses $(0,0,0)$ will eventually prompt this household to spend some time in community 1 . The cheapest community 1 housing available is in period 2, state $L$. This is the one the household will choose first as its wealth rises. Conversely, diminishing the wealth of a household that chooses $(0,1,1)$ will prompt this household to eventually give up some time in community 1 . As community 1 housing is most expensive in state $H$, this is the one the household will give up first as its wealth declines. This is why no household ever chooses $(0,1,0)$. The same argument applies to $\left(1_{B}, 1,0\right)$.

Lemma 4 If $R_{L}<R_{H}$, a native household chooses a location-tenure plan from the subset of alternatives $(0,0,0),(0,0,1),(0,1,1),\left(1_{R}, 0,0\right),\left(1_{R}, 0,1\right)$ and $\left(1_{B}, 1,1\right)$.

Proof: See Appendix A.1.

Fourth, we study how optimal location-tenure plans differ between households with different endowment levels. We already know from Lemma 4 that the higher a household's endowment, the more time it spends in community 1. Here, we ask whether we see increases of the time spent in community 1 in the smallest possible steps. The answer is almost yes. More specifically, we prove:

Lemma 5 Let $R_{L}<R_{H}$. Then:

(i) at least one of the plans $(0,0,1)$ and $\left(1_{R}, 0,1\right)$ is preferred over both $(0,0,0)$ and $\left(1_{B}, 1,1\right)$ at all endowment levels in some set of positive measure;

(ii) at least one of the plans $(0,0,1)$ and $\left(1_{R}, 0,0\right)$ is preferred over both $(0,0,0)$ and $\left(1_{R}, 0,1\right)$ at all endowment levels in some set of positive measure;

(iii) the plan $(0,0,1)$ is preferred over both $(0,0,0)$ and $(0,1,1)$ at all endowment levels in some set of positive measure;

(iv) the plan $\left(1_{R}, 0,1\right)$ is preferred over both $\left(1_{R}, 0,0\right)$ and $\left(1_{B}, 1,1\right)$ at all endowment levels in some set of positive measure.

Proof: See Appendix A.1. 
The newcomers face a much simpler location choice problem. They appear in the second period only if state $H$ occurs, and they thus face a one-period deterministic consumption problem. A newcomer with endowment $\tilde{W}$ moves into community 1 if and only if the utility premium of living there more than outweighs the utility cost of the rent $R_{H}$; that is:

$$
\mu \geq e^{-a\left(\tilde{W}-R_{H}\right)}-e^{-a \tilde{W}}
$$

Note that the right-hand side of this inequality is decreasing in $\tilde{W}$ because of the decreasing marginal utility of numeraire consumption. Therefore if a newcomer chooses community 1 , any other newcomer with a greater endowment chooses community 1 as well.

\subsection{Equilibrium}

An equilibrium is a triple of rents, $\left(R_{1}, R_{H}, R_{L}\right)$, and a period 1 price, $p_{1}$, for homes in community 1 , together with a location-tenure plan for each native household and a location choice for each newcomer. The equilibrium price of homes in community 1 must be such that landlords are indifferent between selling a home in period 1 and renting it in both periods at the equilibrium rents. The equilibrium allocation must be such that housing markets clear and each household's utility is maximized, given its budget constraint and the prices and rents of homes in community 1.

To formulate our main proposition, we need to define $\underline{e}>1$ as the unique real number satisfying the equality

$$
2(1-S)=W^{-1}\left(\frac{1}{a} \ln \left(\frac{\underline{e}-1}{\mu}\right)\right)+W^{-1}\left(\frac{1}{a} \ln \left(\frac{\min \left\{\underline{e}(\underline{e}-1), \mu e^{a W(1)}\right\}}{\mu}\right)\right) .
$$

Proposition 1 There is a unique equilibrium. If

$$
\mu e^{a \tilde{W}(1)}>\underline{e}-1
$$

a positive measure of newcomers choose community 1 in state $H$; the equilibrium prices satisfy $R_{L}<(1+r) R_{1}<R_{H}$ and condition (2); and the location-tenure plans chosen by a positive measure of native households are $(0,0,0),(0,0,1)$ and $\left(1_{R}, 0,0\right)$, plus either

- $(0,1,1)$, and possibly $\left(1_{R}, 0,1\right)$, or

- $\left(1_{R}, 0,1\right)$ and $\left(1_{B}, 1,1\right)$, and possibly $(0,1,1)$. 
If (5) does not hold, all newcomers choose community 0 in state $H$ and the equilibrium prices satisfy $(1+r) R_{1}=R_{L}=R_{H}=(\ln \underline{e}) / a$, so tenure does not matter. The location plans chosen by a positive measure of native households are $(0,0,0),(0,1,1)$ and $(1,0,0)$, plus possibly $(1,1,1)$.

Proof: See Appendix A.1.

Condition (5) depends only on model parameters. Recall that $\tilde{W}(1)$ is the income received by the best-paid newcomer. The inequality ensures that the best-paid newcomer earns a high enough income that he chooses community 1 in equilibrium.

The inequality $R_{L}<R_{H}$ reflects the price pressure newcomers exert when they appear in state $H$. That the opportunity cost of choosing community 1 in the first period, $(1+$ $r) R_{1}$, lies strictly in between $R_{L}$ and $R_{H}$ is then dictated by market clearing. Intuitively, the cost of living in community 1 in period 1 cannot be too different from the cost of living in community 1 in period 2 for sure, a cost that lies in between $R_{L}$ and $R_{H}$.

\section{Income heterogeneity}

In our two-period stochastic model, native households have the options: to vary their housing consumption over time, to choose a state-contingent housing consumption plan, and to choose a tenure mode. The behavior of natives under these circumstances gives rise to income heterogeneity within communities. The fact that native households can own their homes may add further to the heterogeneity of households within communities.

\subsection{State-contingent plans and income mixing}

Note that if some natives choose the plan $(0,1,1)$, Proposition 1 implies that they are indifferent as to the plan $\left(1_{R}, 0,0\right)$ and that both plans are chosen in equilibrium. Consequently, two households with similar incomes may chose different communities in period 1. There are pairs of households in period 1 in which the one with the lower income lives in the nicer community. The households living in the nicer community in period 1 move to the cheaper community in period 2 , and vice versa. Whatever the state in period 2 , there are again pairs of households in which the one with the lower income lives in the nicer community. By definition, this means that communities are not perfectly stratified by income alone in both periods whenever some households choose the plan $(0,1,1)$.

Depending on parameters, either some newcomers move to community 1 in state $H$ or they do not. If no newcomer chooses to live in community 1 , Proposition 1 says that some 
natives choose the plan $(0,1,1)$. By the argument above, in both periods communities are not perfectly stratified according to income alone.

If some newcomers choose to live in community 1 , they affect the distribution of income in that community. Their housing consumption is monotonic with their wealth, which equals their income by assumption. The natives' choice of community is also monotonic with their wealth. The wealth of the natives consists of accumulated income minus any housing costs incurred in period 1 plus, possibly, net capital gains that follow from the purchase of a home in period 1. In general, this implies that the income of the native household indifferent between living in either community is not the same as the income of the newcomer who is at the same point of indifference. This also means that communities are not stratified according to income when newcomers move in.

If state $L$ occurs, there are always pairs of households in which the one with the lower income chooses the nicer community. Proposition 1 implies that the plans $(0,0,1)$ and $\left(1_{R}, 0,0\right)$ are both chosen in equilibrium. Lemma 2 implies that the households that choose $(0,0,1)$ earn less than the households that choose $\left(1_{R}, 0,0\right)$. At the start of period 2 , if state $L$ occurs, the natives who chose $\left(1_{R}, 0,0\right)$ move to the cheaper location, joining there the lowest-income natives in the area. At the same time, the natives who chose $(0,0,1)$ are joining the highest-income natives in community 1 , although they earn less than the households that chose $\left(1_{R}, 0,0\right)$. Therefore, in state $L$, communities are not stratified according to income.

To illustrate the argument, we solve the model for a specific set of parameters. We report the proportions of households who live in community 1 for each level of income in Figure 2 for period 1, Figure 3 for period 2 state $H$, and Figure 4 for period 2 state $L{ }^{1}$ The computed equilibrium has the property that households are indifferent between the plans $\left(1_{R}, 0,0\right)$ and $(0,1,1)$.

In period 1, the computed equilibrium displays the type of imperfect stratification found in models with both income and preference heterogeneity: the supports of the income distributions in each community are overlapping intervals. Here, the imperfect stratification comes from the fact that the households who choose to spend a total of one period in community 1 over their life are indifferent between living in community 1 in period 1 or in period 2. As shown in Figure 2, these are the households with income between 3.05 and 5.45 in period 1. Figure 3 shows the difference between natives' and newcomers' location choice in state $H$. The support of the income distribution of native

\footnotetext{
${ }^{1}$ The figures are drawn assuming the following parameter values: $a=5, \nu=.4, \mu=8, \pi=.2, r=.05$, $S=.499, \tilde{W}(n)=8 n$, and $w_{t}(i)=8 i$ for $t=1,2$. The equilibrium rents are $R_{1}=5.645, R_{H}=6.244$ and $R_{L}=5.253$.
} 


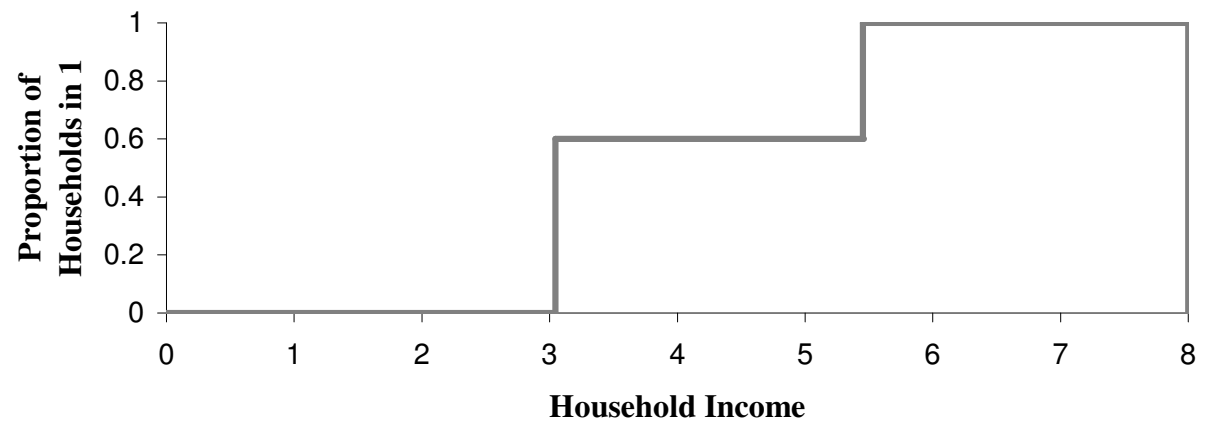

Figure 2: Proportions of native households in community 1 by income - Period 1

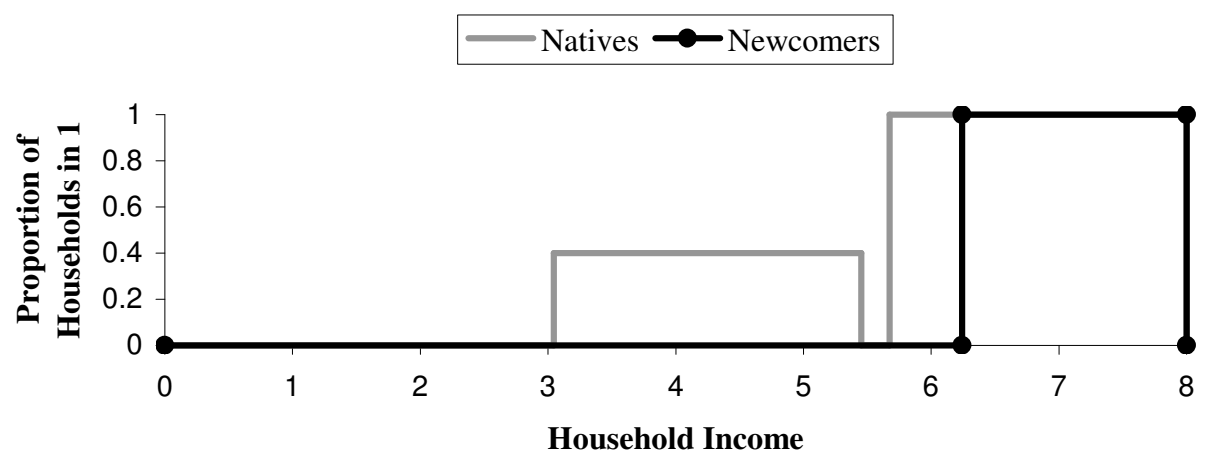

Figure 3: Proportions of households in community 1 by income - Period 2, state $\mathrm{H}$

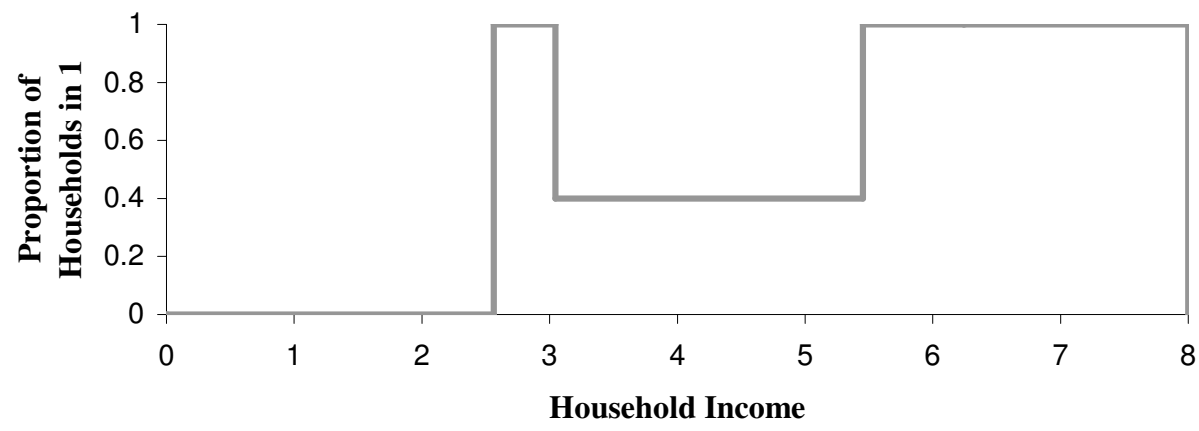

Figure 4: Proportions of native households in community 1 by income - Period 2, state L 
households living in community 1 is not convex in this state. In state $L$, Figure 4 implies that the support of the income distribution in community 0 is not convex.

In all, we learn that optimal household choices yield an equilibrium where communities are not stratified according to income alone, for sure in period 2, and possibly in period 1. The underlying reason is that knowing a household's income at a particular point in time is not sufficient to predict its housing consumption plan. First, past housing experiences affect the relationship between the household's wealth and its current income. More important, because of the diversity of equilibrium housing choices, the relationship between wealth and income does not remain monotonic over time.

Furthermore, wealth itself is not sufficient to predict a household's community choice. Two households with identical wealth may choose different communities simply because they have different housing consumption plans for the future.

\subsection{Tenure choice and income mixing}

Proposition 1 implies that when the richest native households choose to live in community 1 for the two periods, they buy their homes in period 1. The next-poorer natives rent in community 1 in period 1 and remain there only if state $L$ occurs. The households indifferent between the two plans have accumulated earnings $W$ so that the utilities they derive from each plan are equal; that is:

$$
\begin{aligned}
-e^{-a\left(W-(1+r) R_{1}-\bar{R}_{2}\right)}+2 \mu= & \pi\left(-e^{-a\left(W-(1+r) R_{1}\right)}+\mu\right) \\
& +(1-\pi)\left(-e^{-a\left(W-(1+r) R_{1}-R_{L}\right)}+2 \mu\right),
\end{aligned}
$$

or

$$
\mu e^{a\left(W-(1+r) R_{1}\right)}=e^{a R_{H}}-1+\frac{e^{a \bar{R}_{2}}-\pi e^{a R_{H}}-(1-\pi) e^{a R_{L}}}{\pi} .
$$

If ownership were not an option, the plan $\left(1_{R}, 1,1\right)$ would replace $\left(1_{B}, 1,1\right)$ as the plan offering the greatest utility of housing. A similar derivation yields that the households indifferent between $\left(1_{R}, 1,1\right)$ and $\left(1_{R}, 0,1\right)$ would be the ones with accumulated earnings $W$ defined by

$$
\mu e^{a\left(W-(1+r) R_{1}\right)}=e^{a R_{H}}-1
$$

The endowment level that solves equation (8) is higher than the endowment level that solves (7) because the third term on the right-hand side of (7) is negative. This term captures the benefit of the insurance provided by a purchase in period 1 . That is, 
an owner pays expected second-period rent, $\bar{R}_{2}$, instead of $R_{H}$ with probability $\pi$ and $R_{L}$ with probability $1-\pi$. Therefore, at the equilibrium rents, if ownership were not an option, fewer native households would choose to stay in location 1 in state $H$. Equilibrium rents would be different if ownership were not an option.

To analyze whether changes in rents would compensate the difference in natives' demand for community 1 in state $H$, we compare the benchmark equilibrium to a rental-only equilibrium, amending the benchmark model by removing the right to purchase a home. We prove in Appendix A.5 that this rental-only economy has a unique equilibrium. Furthermore, if model parameters are such that a positive measure of newcomers choose community 1 in state $H$ and a positive measure of native households choose the plan $\left(1_{B}, 1,1\right)$ in the benchmark economy, then the equilibrium rents in the two economies display the relationship:

$$
R_{1}^{r} \leq R_{1}^{b}, \quad R_{H}^{r}<R_{H}^{b}, \quad R_{L}^{r} \geq R_{L}^{b}
$$

where the superscripts $r$ and $b$ distinguish variables in the rental-only economy from their counterparts in the benchmark economy.

The difference between the benchmark and the rental-only economy amounts to a downward shift in the natives' demand for community 1 in state $H$. This downward shift implies that $R_{H}$ must be lower in the rental-only economy. A lower $R_{H}$ raises the demand for community 1 not only from natives but also from newcomers. Therefore, when state $H$ occurs, fewer natives remain in community 1 than when ownership is an option.

Rents in period 1 and in state $L$ may also differ between the rental-only and the benchmark economy. This is because the lower $R_{H}$ in the rental-only economy may prompt some households that choose the plan $\left(1_{R}, 0,0\right)$ in the benchmark economy to choose $(0,1,1)$ in the rental-only economy. In this case, the rents $R_{1}$ and $R_{L}$ cannot be identical in the two economies. The shift from $\left(1_{R}, 0,0\right)$ to $(0,1,1)$ implies a lower demand for location 1 in period 1 and a higher demand for location 1 in state $L$ in the rental-only economy. This explains why $R_{1}$ may be lower and $R_{L}$ may be higher in the rental-only economy.

Alternatively, if no household chooses $(0,1,1)$ in the rental-only economy, then the same is true in the ownership economy. In this case, there is no effect on demand in period 1 and period 2, state $L$, and the rents $R_{1}$ and $R_{L}$ are the same in both economies. This explains the weak inequalities for $R_{1}$ and $R_{L}$ in (9).

Overall, the difference in equilibrium rents between the benchmark and the rentalonly economy does not fully offset the drop in demand for location 1 in state $H$ by native 


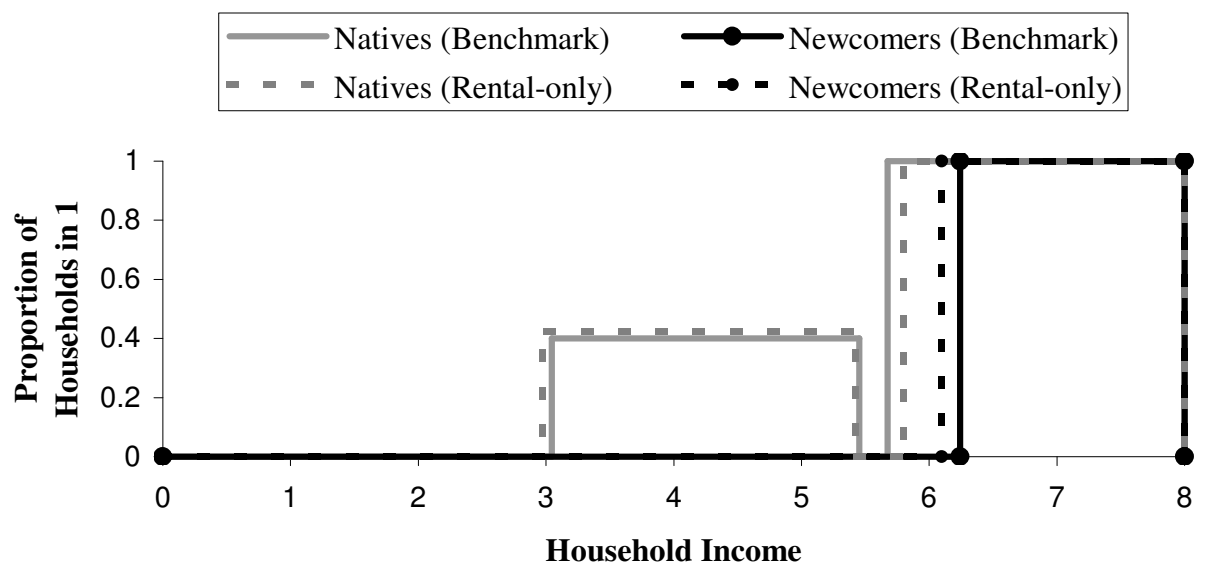

Figure 5: Proportions of households in community 1 by income - Period 2, state $\mathrm{H}$

households. More newcomers move to location 1 in the rental-only economy than in the benchmark economy, taking advantage of the lower rent in state $H$.

Allowing households to own their home therefore widens the difference between the average income of the newcomers who move to location 1 and the average income of the natives who stay in location 1 in period 2 when state $H$ occurs. Some poorer native households stay put in location 1 in state $H$ when ownership is an option, while the income distribution of the newcomers who choose location 1 is truncated at a higher level. The newcomers who choose location 1 are richer on average. Unless the average income of newcomers located in 1 is lower than the average income of their native neighbors, this difference in averages implies greater income dispersion under homeownership than in the rental-only economy.

To illustrate the above result, we report in Figure 5 the proportions of households who live in community 1 in state $H$ in the benchmark economy and in the rental-only economy, as a function of household income. We use the same parameters as in the earlier example. $^{2}$

\subsection{Empirical evidence}

Ioannides (2004) finds a positive correlation between the income dispersion within a neighborhood and the average time since households moved into the neighborhood. A high average can be associated with either a high or a low dispersion of the time since each household moved in. We therefore ask whether there is a positive correlation between

\footnotetext{
${ }^{2}$ Rents in the rental-only equilibrium are: $R_{1}=5.517, R_{H}=6.099$ and $R_{L}=5.320$.
} 
the income dispersion in a neighborhood and the dispersion of the time since a household moved to the neighborhood.

Table 1 presents summary statistics for the neighborhood cluster sample of the American Housing Survey for the years 1985, 1989 and 1993.

We regress the coefficient of variation of neighborhood income on the standard deviation of the years since each household moved into the neighborhood. Results reported in Table 2 indicate that neighborhoods with a high standard deviation of time since each household moved in are neighborhoods with a significantly higher dispersion of income.

To examine further whether the discrepancy between the income of newcomers and the income of households that moved into the neighborhood earlier is a significant contributor to neighborhood income heterogeneity, we focus on a household's income relative to that of its neighbors. Results are reported in Table 3.

We find that the shorter the time since a household moved into the neighborhood, the higher its income relative to its neighbors' income. Over the period of the study, almost all neighborhoods were located in MSAs that enjoyed housing price growth.

When we restrict the sample to owners only, the same results hold, but when we restrict the sample to renters only, the significant negative relationship disappears.

The AHS gives an estimate of property value for the sub-sample of owners. We find a significant positive relationship between the relative value of a household's home and its relative income. The negative relationship between the relative income of a household and the relative number of years since it moved in remains when we control for relative property values. (Both the income and the time-since-moved variables are a household's own value divided by the neighborhood mean. The same results obtain when we consider the sub-sample of owners and use the mean of the neighborhood owners as benchmarks.)

This evidence together with the evidence in the literature suggests that the mechanisms generating income heterogeneity within our model are empirically relevant.

\section{Concluding remarks}

The standard explanation for the income mixing we see within US metropolitan neighborhoods is that households differ in their preferences for various local amenities. We propose a complementary explanation. By setting the community choice problem in a dynamic and stochastic environment, we show that income mixing arises even if households have 
Table 1: Summary statistics

\begin{tabular}{|c|c|c|c|c|c|c|}
\hline \multirow[b]{2}{*}{ Variable } & \multicolumn{2}{|c|}{1985} & \multicolumn{2}{|c|}{1989} & \multicolumn{2}{|c|}{1993} \\
\hline & Mean & S.D. & Mean & S.D. & Mean & S.D. \\
\hline \multicolumn{7}{|l|}{ — Neighborhoods — } \\
\hline C.V. income & 0.548 & 0.214 & 0.572 & 0.212 & 0.575 & 0.215 \\
\hline S.D. time since moved & 9.603 & 5.966 & 10.553 & 5.824 & 11.196 & .5 .929 \\
\hline \multicolumn{7}{|l|}{ — All households - } \\
\hline Income & 30085 & 24929 & 36175 & 30010 & 38220 & 32081 \\
\hline Time since moved & 10.25 & 11.64 & 10.87 & 12.18 & 11.64 & 12.92 \\
\hline \multicolumn{7}{|l|}{ - Owners - } \\
\hline Income & 35820 & 26446 & 42636 & 32293 & 45905 & 34740 \\
\hline Time since moved & 14.02 & 12.33 & 14.77 & 12.91 & 16.17 & 13.77 \\
\hline Property value & 79427 & 53454 & 112466 & 87655 & 109929 & 79557 \\
\hline \multicolumn{7}{|l|}{ - Renters - } \\
\hline Income & 21125 & 19156 & 25814 & 22326 & 26255 & 22752 \\
\hline Time since moved & 4.34 & 7.23 & 4.63 & 7.48 & 4.60 & 7.11 \\
\hline
\end{tabular}

Table 2: Coefficient of variation of neighborhood income

\begin{tabular}{llll}
\hline \hline & 1985 & 1989 & 1993 \\
Year & & & \\
Intercept & 0.4831 & 0.4855 & 0.5098 \\
& $(0.0182)^{*}$ & $(0.0183)^{*}$ & $(0.0169)^{*}$ \\
S.D. time since moved & 0.0067 & 0.0082 & 0.0058 \\
& $(0.0016)^{*}$ & $(0.0015)^{*}$ & $(0.0013)^{*}$ \\
$R^{2}$ & 0.035 & 0.050 & 0.026 \\
Number of observations & 486 & 545 & 730 \\
\hline *Indicates statistical significance at the 0.05 level.
\end{tabular}


Table 3: Household income relative to neighbors' income

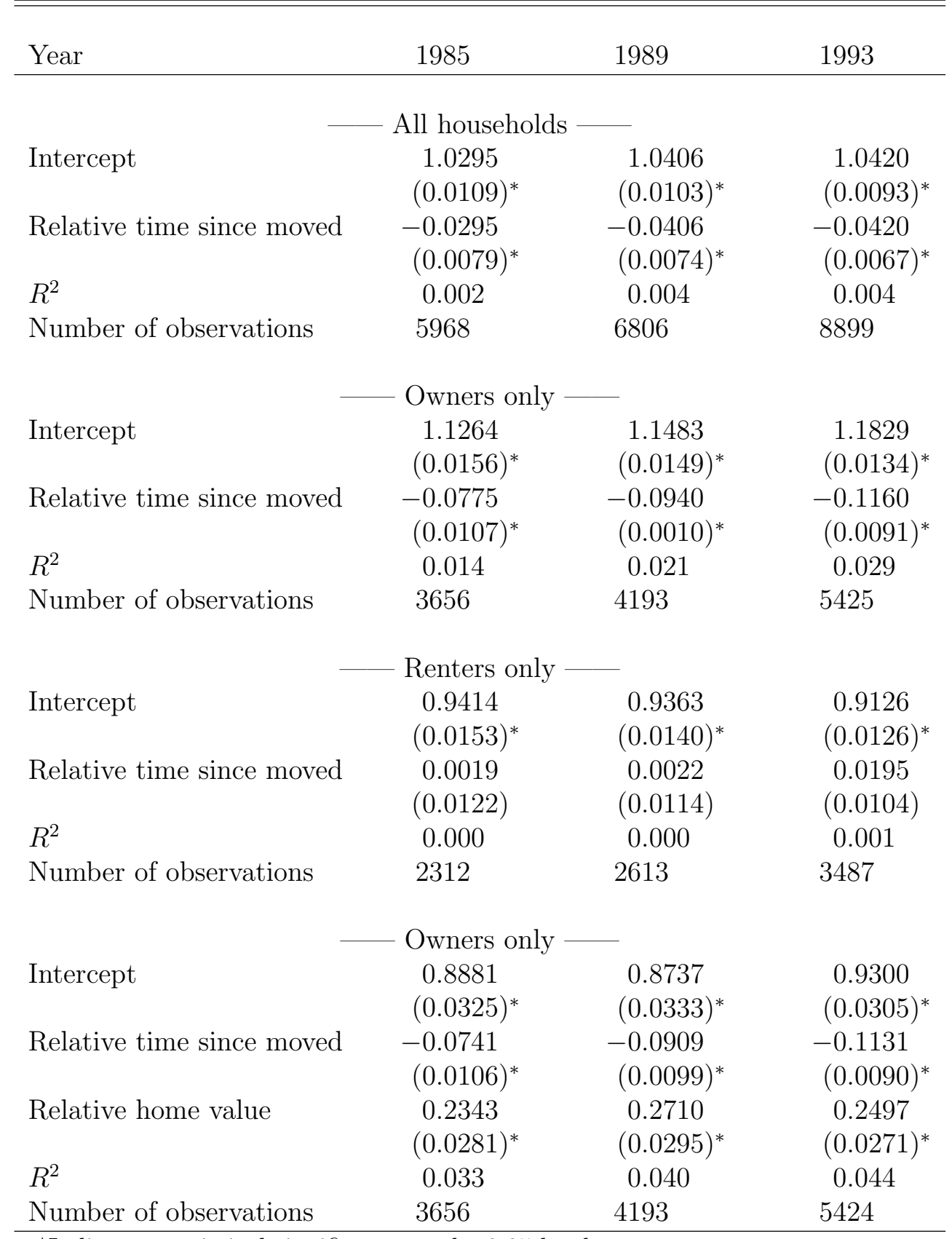

*Indicates statistical significance at the 0.05 level. 
identical standard preferences and there is a homogeneous stock of housing within each neighborhood.

Our analysis sheds new light on policies that distort housing consumption. For example, when property taxes depend on the purchase price of a home and not its current value, buying a home provides a hedge not only against future rent risk but also against future tax liabilities risk. This kind of policy reinforces the effects of ownership on the composition of neighborhoods that our model identifies.

Our findings raise questions about empirical research that relies on cross-sectional observations of household income and housing choice to estimate demand functions for local amenities. If the reason behind observed differences in location choices between households with identical income is not a difference in preferences, then a household's income and location choice is not sufficient to infer its preferences or its willingness to pay for local amenities.

\section{References}

Bénabou, Roland (1996a): "Equity and Efficiency in Human Capital Investment: The Local Connection," Review of Economic Studies, 63:237-264.

Bénabou, Roland (1996b): "Heterogeneity, Stratification, and Growth: Macroeconomic Implications of Community Structure and School Finance," American Economic Review, 86:584-609.

Berglas, Eitan (1976): "Distribution of Tastes and Skills, and the Provision of Local Public Goods," Journal of Public Economics, 6:409-423.

Berglas, Eitan, and David Pines (1981): "Clubs, Local Public Goods and Transportation Models: A Synthesis," Journal of Public Economics, 15:141-162.

Brueckner, Jan K. (1994): "Tastes, Skills and Local Public Goods," Journal of Urban Economics, 35:201-220.

Davidoff, Thomas (2003): "Labor Income, Housing Prices and Homeownership," Fisher Center for Real Estate \& Urban Economics, Fisher Center Working Papers, Paper 289.

Davidoff, Thomas (2004): "Income Sorting: Measurement and Decomposition," Fisher Center for Real Estate \& Urban Economics, University of California Berkeley, Fisher Center Working Papers, Paper 291. 
de Bartolome, Charles A.M., and Stephen L. Ross (2003): "Equilibria with Local Governments and Commuting: Income Sorting vs Income Mixing," Journal of Urban Economics, 54:1-20.

Diaz-Serrano, Luis (2004): "On the Negative Relationship between Labor Income Uncertainty and Homeownership: Risk Aversion vs. Credit Constraints," Discussion Paper No. 1208, Institute for the Study of Labor (IZA), Bonn.

Durlauf, Steven N. (1996): "A Theory of Persistent Income Inequality," Journal of Economic Growth, 1:75-93.

Ellickson, Bryan (1971): "Jurisdictional Fragmentation and Residential Choice," American Economic Review, 61:334-39.

Epple, Dennis, and Glenn J. Platt (1998): "Equilibrium and Local Redistribution in an Urban Economy when Households Differ in Both Preferences and Incomes," Journal of Urban Economics, 43:23-51.

Epple, Dennis, and Holger Sieg (1999): "Estimating Equilibrium Models of Local Jurisdictions," Journal of Political Economy, 107:645-681.

Fernandez, Raquel, and Richard Rogerson (1996): "Income Distribution, Communities, and the Quality of Public Education," Quarterly Journal of Economics, 111:135-164.

Fernandez, Raquel, and Richard Rogerson (1998): "Public Education and Income Distribution: A Dynamic Quantitative Evaluation of Education-Finance Reform," American Economic Review, 88:813-833.

Gyourko, Joseph, Christopher J. Mayer, and Todd Sinai (2004): "Superstar Cities," mimeo, University of Pennsylvania.

Han, Lu (2004): "The Effects of Price Uncertainty on Housing Demand in the Presence of Lumpy Transaction Costs," mimeo, Stanford University.

Hardman, Anna, and Yannis M. Ioannides (2004): "Neighbors' Income Distribution: Economic Segregation and Mixing in US Urban Neighborhoods," Journal of Housing Economics, 13:368-382.

Henderson, Vernon (1991): "Separating Tiebout Equilibrium," Journal of Urban Economics, 29:128-152.

Hilber, Christian A.L. (2005): "Neighborhood Externality Risk and the Homeownership Status of Properties," Journal of Urban Economics, 57:213-241. 
Ioannides, Yannis M. (2004): "Neighborhood Income Distributions," Journal of Urban Economics, 56:435-457.

Keely, Louise (2004): "A Theory of Community Formation," mimeo, University of WisconsinMadison.

McGuire, Martin C. (1991): "Group Composition, Collective Consumption, and Collaborative Production," American Economic Review, 81:1391-1407.

Nechyba, Thomas J. (2000): "Mobility, Targeting, and Private-School Vouchers," American Economic Review, 90:130-146.

Ortalo-Magné, François, and Sven Rady (2002): "Tenure Choice and the Riskiness of Non-Housing Consumption," Journal of Housing Economics, 11:266-279.

Sinai, Todd, and Nicholas Souleles (forthcoming): "Owner-Occupied Housing as a Hedge Against Rent Risk," Quarterly Journal of Economics.

Stiglitz, Joseph E. (1983): "Public Goods in Open Economies with Heterogeneous Individuals," in J.-F. Thisse, H.G. Zoller (Eds.), Location Analysis of Public Facilities, North-Holland, Amsterdam, pp. 55-78. 


\section{Appendix}

\section{A.1 Proofs}

To ease the notational burden, we define

$$
e_{1}=e^{a(1+r) R_{1}}, \quad e_{H}=e^{a R_{H}}, \quad e_{L}=e^{a R_{L}}, \quad e_{2}=e^{a \bar{R}_{2}} .
$$

Proof of Lemma 4: In view of Lemma 1, it is enough to show that the plans $\left(1_{B}, 1,0\right)$ and $(0,1,0)$ are never optimal. We deal with $\left(1_{B}, 1,0\right)$ first.

Suppose $\pi>\frac{1}{2}$. Let $W_{1}$ be the endowment level at which a native household would be indifferent between the plans $\left(1_{R}, 0,1\right)$ and $\left(1_{B}, 1,1\right)$, and $W_{2}$ the endowment level at which it would be indifferent between the plans $\left(1_{R}, 0,1\right)$ and $\left(1_{B}, 1,0\right)$. To show that the plan $\left(1_{B}, 1,0\right)$ is never optimal, it suffices to show that $W_{1}<W_{2}$. To see this, recall from Section 2.2 that if the expected utility curves of two plans cross, the curve associated with the plan that promises a larger amount of housing consumption in location 1 ex ante is steeper at all endowment levels. The curve associated with $\left(1_{B}, 1,1\right)$ is above the curve associated with $\left(1_{R}, 0,1\right)$ to the right of $W_{1}$, and the curve associated with $\left(1_{R}, 0,1\right)$ is above the curve associated with $\left(1_{B}, 1,0\right)$ to the left of $W_{2}$. If $W_{1}<W_{2}$, this implies that the curve associated with $\left(1_{B}, 1,0\right)$ is everywhere below the upper envelope of the curves associated with $\left(1_{R}, 0,1\right)$ and $\left(1_{B}, 1,1\right)$.

It is straightforward to verify that the endowment levels $W_{1}$ and $W_{2}$ are defined by

$$
\begin{aligned}
\mu e^{a W_{1}} & =\frac{1}{\pi} e_{1}\left[e_{2}-\pi-(1-\pi) e_{L}\right] \\
\mu e^{a W_{2}} & =\frac{1}{1-2 \pi} e_{1}\left[(1-\pi)\left(e_{L}-\frac{e_{2}}{e_{L}}\right)-\pi\left(e_{2}-1\right)\right] .
\end{aligned}
$$

It is easy to show that $W_{1}<W_{2}$ if and only if $e_{2}>e_{L}$, which in turn is equivalent to $R_{L}<R_{H}$.

Now suppose $\pi<\frac{1}{2}$. Let $W_{3}$ be the endowment level at which a native household would be indifferent between the plans $\left(1_{R}, 0,1\right)$ and $\left(1_{R}, 0,0\right)$ :

$$
\mu e^{a W_{3}}=e_{1}\left(e_{L}-1\right) .
$$

The plan $\left(1_{B}, 1,0\right)$ is never optimal if $W_{2}<W_{3}$. This inequality is easily seen to be equivalent to $e_{2}>e_{L}$.

In the case where $\pi=\frac{1}{2}$, a comparison of expected utilities shows that for $e_{2}>e_{L}$, the plan $\left(1_{R}, 0,1\right)$ is preferred to $\left(1_{B}, 1,0\right)$ at all endowment levels. This completes the proof that $\left(1_{B}, 1,0\right)$ is never optimal.

Turning to $(0,1,0)$, suppose $\pi>\frac{1}{2}$. Let $W_{4}$ be the endowment level at which a native household would be indifferent between the plans $(0,1,0)$ and $(0,1,1)$, and $W_{5}$ the endowment level at which it would be indifferent between the plans $(0,0,1)$ and $(0,1,0)$ :

$$
\begin{aligned}
\mu e^{a W_{4}} & =e_{L}-1, \\
\mu e^{a W_{5}} & =\frac{1-\pi}{1-2 \pi}\left(e_{L}-1\right)-\frac{\pi}{1-2 \pi}\left(e_{H}-1\right) .
\end{aligned}
$$

The plan $(0,1,0)$ is never optimal if $W_{4}<W_{5}$. It is easy to verify that this inequality is equivalent to $e_{L}<e_{H}$.

Next suppose $\pi<\frac{1}{2}$. Let $W_{6}$ be the endowment level at which a native household would be indifferent between the plans $(0,0,0)$ and $(0,0,1)$, and $W_{7}$ the endowment level at which it would be indifferent between the plans $(0,0,0)$ and $(0,1,0)$ :

$$
\begin{aligned}
& \mu e^{a W_{6}}=e_{L}-1, \\
& \mu e^{a W_{7}}=e_{H}-1 .
\end{aligned}
$$

The plan $(0,1,0)$ is never optimal if $W_{6}<W_{7}$, which is obviously the same as $e_{L}<e_{H}$.

In the case where $\pi=\frac{1}{2}$, a comparison of expected utilities shows that for $e_{L}<e_{H}$, the plan $(0,0,1)$ is preferred to $(0,1,0)$ at all endowment levels. This completes the proof. 
Proof of Lemma 5: Part (i): Let $W_{1}$ be the endowment level at which a native household would be indifferent between the plans $(0,0,0)$ and $\left(1_{R}, 0,1\right)$, and $W_{2}$ the endowment level at which it would be indifferent between the plans $\left(1_{R}, 0,1\right)$ and $\left(1_{B}, 1,1\right)$. To show that the plan $\left(1_{R}, 0,1\right)$ is preferred to both $(0,0,0)$ and $\left(1_{B}, 1,1\right)$ on a set of endowment levels of positive measure, it is enough to show that $W_{1}<W_{2}$. To see this, recall from Section 2.2 that if the expected utility curves of two plans cross, the curve associated with the plan that promises a larger amount of housing consumption in location 1 ex ante is steeper at all endowment levels. The curve associated with $\left(1_{R}, 0,1\right)$ is above the curve associated with $(0,0,0)$ to the right of $W_{1}$, and above the curve associated with $\left(1_{B}, 1,1\right)$ to the left of $W_{2}$. If $W_{1}<W_{2}$, therefore, $\left(1_{R}, 0,1\right)$ is preferred to both $(0,0,0)$ and $\left(1_{B}, 1,1\right)$ at all wealth levels strictly between $W_{1}$ and $W_{2}$. It is straightforward to verify that the endowment levels $W_{1}$ and $W_{2}$ are defined by

$$
\begin{aligned}
\mu e^{a W_{1}} & =\frac{1}{2-\pi}\left[\pi e_{1}+(1-\pi) e_{1} e_{L}-1\right], \\
\mu e^{a W_{2}} & =\frac{e_{1}}{\pi}\left[e_{2}-\pi-(1-\pi) e_{L}\right] .
\end{aligned}
$$

It is easy to see that $W_{1}<W_{2}$ if and only of $2(1-\pi) e_{1}\left(e_{2}-e_{L}\right)+\pi\left[e_{1} e_{2}-2 e_{1}+1\right]>0$. As $e_{L}<e_{H}$, we have $e_{2}>e_{L}$. If $e_{2} \geq e_{1}$, we also have $e_{1} e_{2}-2 e_{1}+1 \geq\left(e_{1}-1\right)^{2}$, so $e_{2} \geq e_{1}$ is a sufficient condition for $W_{1}<W_{2}$, and hence for $\left(1_{R}, 0,1\right)$ to be preferred to $(0,0,0)$ and $\left(1_{B}, 1,1\right)$ on some open interval of endowment levels.

Next, let $W_{3}$ be the endowment level at which a native household would be indifferent between the plans $(0,0,0)$ and $(0,0,1)$, and $W_{4}$ the endowment level at which it would be indifferent between the plans $(0,0,0)$ and $\left(1_{B}, 1,1\right)$ :

$$
\begin{aligned}
\mu e^{a W_{3}} & =e_{L}-1 \\
\mu e^{a W_{4}} & =\frac{1}{2-\pi}\left[e_{1} e_{2}-\pi-(1-\pi) e_{L}\right]
\end{aligned}
$$

It is easy to see that $W_{3}<W_{4}$ if and only of $e_{1} e_{2}-2 e_{2}+1+2\left(e_{2}-e_{L}\right)>0$. As $e_{L}<e_{H}$, we have $e_{2}>e_{L}$. If $e_{1} \geq e_{2}$, we also have $e_{1} e_{2}-2 e_{2}+1 \geq\left(e_{2}-1\right)^{2}$, so $e_{1} \geq e_{2}$ is a sufficient condition for $W_{3}<W_{4}$, and hence for $(0,0,1)$ to be preferred to $(0,0,0)$ and $\left(1_{B}, 1,1\right)$ on some open interval of endowment levels.

Part (ii): An argument similar to the one used for part (i) shows first that for $e_{1} \leq e_{L},\left(1_{R}, 0,0\right)$ is preferred to $(0,0,0)$ and $\left(1_{R}, 0,1\right)$ on some open interval of endowment levels; and second, that for $e_{1} \geq e_{L},(0,0,1)$ is preferred to $(0,0,0)$ and $\left(1_{R}, 0,1\right)$ on some open interval of endowment levels.

Part (iii): Let $W_{5}$ be the endowment level at which a native household would be indifferent between the plans $(0,0,0)$ and $(0,1,1)$, and $W_{6}$ the endowment level at which it would be indifferent between the plans $(0,0,1)$ and $(0,1,1)$ :

$$
\begin{aligned}
\mu e^{a W_{5}} & =\pi e_{H}+(1-\pi) e_{L}-1, \\
\mu e^{a W_{6}} & =e_{H}-1 .
\end{aligned}
$$

It suffices to show that $W_{5}<W_{6}$. This is easily seen to be equivalent to $e_{L}<e_{H}$.

Part (iv): Let $W_{7}$ be the endowment level at which a native household would be indifferent between the plans $\left(1_{R}, 0,0\right)$ and $\left(1_{B}, 1,1\right)$, and $W_{8}$ the endowment level at which it would be indifferent between the plans $\left(1_{R}, 0,1\right)$ and $\left(1_{B}, 1,1\right)$ :

$$
\begin{aligned}
\mu e^{a W_{7}} & =e_{1}\left(e_{2}-1\right), \\
\mu e^{a W_{8}} & =e_{1}\left[e_{2}-1+\frac{1-\pi}{\pi}\left(e_{2}-e_{1}\right)\right] .
\end{aligned}
$$

It suffices to show that $W_{7}<W_{8}$. This is easily seen to be equivalent to $e_{L}<e_{2}$, which in turn is the same as $e_{L}<e_{H}$.

Proof of Proposition 1: The proof draws on auxiliary results that are established in Sections A.2A.4 of this appendix. Lemma A.6 shows that in equilibrium, second period rents satisfy $R_{L}<R_{H}$ if a positive measure of newcomers choose location 1 , and $R_{L}=R_{H}$ otherwise. Lemma A.11 shows that (2) 
holds if $R_{L}<R_{H}$. Lemmas A.8 and A.9 show that equilibrium configurations must be as stated in the proposition. This implies that the relevant market clearing conditions are (A.26)-(A.29). Lemma A.12 shows that these conditions are equivalent to the system of equations (A.30)-(A.33). Lemmas A.13 and A.14 show that this system admits a unique solution with $R_{L} \leq R_{H}$ and the properties stated in the proposition. Lemma A.15 shows that this solution yields an equilibrium.

\section{A.2 Auxiliary results on household behavior}

If $R_{L}>R_{H}$, the roles of the two states in period 2 are reversed. The three results below are therefore just mirror images of Lemmas 1, 4, and 5, respectively, and do not require individual proofs.

Lemma A.1 If $R_{L}>R_{H}$, a native household wanting to live in location 1 in the first period prefers to own its home if and only if it plans to stay in location 1 should state L occur in the second period.

Lemma A.2 If $R_{L}>R_{H}$, a native household chooses a location-tenure plan from the following subset of available options: $(0,0,0),(0,1,0),(0,1,1),\left(1_{R}, 0,0\right),\left(1_{R}, 1,0\right)$ and $\left(1_{B}, 1,1\right)$.

Lemma A.3 Let $R_{L}>R_{H}$. Then:

(i) at least one of the plans $(0,1,0)$ and $\left(1_{R}, 1,0\right)$ is preferred to both $(0,0,0)$ and $\left(1_{B}, 1,1\right)$ at all endowment levels in some set of positive measure;

(ii) at least one of the plans $(0,1,0)$ and $\left(1_{R}, 0,0\right)$ is preferred to both $(0,0,0)$ and $\left(1_{R}, 1,0\right)$ at all endowment levels in some set of positive measure;

(iii) the plan $(0,1,0)$ is preferred to both $(0,1,1)$ and $(0,0,0)$ at all endowment levels in some set of positive measure;

(iv) the plan $\left(1_{R}, 1,0\right)$ is preferred to both $\left(1_{B}, 1,1\right)$ and $\left(1_{R}, 0,0\right)$ at all endowment levels in some set of positive measure.

If $R_{H}=R_{L}$, the tenure mode is irrelevant, so native households' decisions concern location only.

Lemma A.4 If $R_{L}=R_{H}$, each of the location plans $(1,1,0),(1,0,1),(0,1,0)$ and $(0,0,1)$ is optimal for a native household at precisely one endowment level, and suboptimal at all other endowment levels. Thus, only the plans $(0,0,0),(0,1,1),(1,0,0)$ and $(1,1,1)$ may be chosen by a positive measure of native households.

Proof: The first statement follows if we let $R_{L}$ tend to $R_{H}$ in Lemmas 4 and A.2. The second statement follows trivially from the first.

Lemma A.5 Let $R_{L}=R_{H}$. If the location plans $(1,1,1)$ and $(0,0,0)$ are optimal at some endowment levels, then one of the plans $(1,0,0)$ and $(0,1,1)$ is preferred to both $(1,1,1)$ and $(0,0,0)$ on a set of endowment levels of positive measure.

Proof: As $R_{L}=R_{H}$, we have $e_{L}=e_{H}=e_{2}$, for which we shall write $e_{*}$.

Let $W_{1}$ be the endowment level at which a native household would be indifferent between the plans $(0,0,0)$ and $(1,0,0)$, and $W_{2}$ the endowment level at which it would be indifferent between the plans $(1,0,0)$ and $(1,1,1)$ :

$$
\begin{aligned}
& \mu e^{a W_{1}}=e_{1}-1, \\
& \mu e^{a W_{2}}=e_{1}\left(e_{*}-1\right) .
\end{aligned}
$$

Thus, $W_{1}<W_{2}$ if and only if $e_{1}\left(e_{*}-e_{1}\right)+\left(e_{1}-1\right)^{2}>0$, a sufficient condition for which is $e_{*} \geq e_{1}$. 
Next, let $W_{3}$ be the endowment level at which a native household would be indifferent between the plans $(0,0,0)$ and $(0,1,1)$, and $W_{4}$ the endowment level at which it would be indifferent between the plans $(0,1,1)$ and $\left(1_{B}, 1,1\right)$ :

$$
\begin{aligned}
\mu e^{a W_{3}} & =e_{*}-1, \\
\mu e^{a W_{4}} & =e_{*}\left(e_{1}-e_{*}\right) .
\end{aligned}
$$

Thus, $W_{3}<W_{4}$ if and only if $e_{*}\left(e_{1}-e_{*}\right)+\left(e_{*}-1\right)^{2}>0$, a sufficient condition for which is $e_{1} \geq e_{*}$. This implies that at least one of the inequalities $W_{1}<W_{2}$ and $W_{3}<W_{4}$ always holds.

\section{A.3 Auxiliary results on equilibrium prices and configurations}

In the following, we shall write $D_{1}, D_{H}$, and $D_{L}$ for native households' aggregate demand for housing in location 1 in period 1 ; period 2 , state $H$; and period 2 , state $L$, respectively.

Lemma A.6 In equilibrium, second-period rents satisfy $R_{L}<R_{H}$ if a positive measure of newcomers choose location 1 , and $R_{L}=R_{H}$ otherwise.

Proof: Suppose that $R_{L} \geq R_{H}$ with a positive measure of newcomers choosing location 1 in state $H$. Then, Lemmas A.2 and A.4 imply that $D_{L} \leq D_{H}$. Aggregate demand for housing in location 1 by native households and newcomers is therefore higher in state $H$ than in state $L$. Given that the supply of housing in location 1 is the same in both states, this is incompatible with market clearing. This proves the first part of the lemma.

Next, suppose that $R_{L}<R_{H}$ with all newcomers choosing location 0 in state $H$. Then, market clearing implies $D_{H}=D_{L}$, which in turn implies that the plans $\left(1_{R}, 0,1\right)$ and $(0,0,1)$ are not chosen by any native households. This contradicts parts (ii) and (iii) of Lemma 5 unless either $\left(1_{R}, 0,0\right)$ and $(0,1,1)$ are the only plans chosen (in which case they are chosen in equal measure), or $\left(1_{B}, 1,1\right)$ and $(0,0,0)$ are the only plans chosen. The first alternative contradicts our assumption that $S<\frac{1}{2}$, the second contradicts part (i) of Lemma 5. A similar argument involving Lemma A.3 instead of Lemma 5 shows that the inequality $R_{L}>R_{H}$ is also incompatible with no newcomers choosing location 1 in state $H$. This proves the second part of the lemma.

Lemma A.7 In any equilibrium, the plan $(0,0,0)$ is chosen by a positive measure of native households.

Proof: From Lemma A.6, we know that $R_{L} \leq R_{H}$. From Lemmas 4 and A.4, we know that the only housing consumption plans that may be chosen by a positive measure of native households are $(1,1,1)$, $(1,0,1),(1,0,0),(0,1,1),(0,0,1)$ and $(0,0,0)$. We write $m_{111}$ for the measure of native households choosing $(1,1,1), m_{101}$ for the measure of native households choosing $(1,0,1)$ etc.

Now suppose $m_{000}=0$. Then, market clearing in period 1 implies $m_{001}+m_{011}=1-S$; market clearing in period 2 , state $L$ implies $m_{100}=1-S$. Adding these two equations yields $m_{001}+m_{011}+m_{100}=$ $2(1-S)>1$, which contradicts the fact that the total native population has size 1 .

Lemma A.8 In an equilibrium where a positive measure of newcomers choose location 1 in state $H$, the location-tenure plans chosen by a positive measure of native households are $(0,0,0),(0,0,1)$, and $\left(1_{R}, 0,0\right)$, plus either
(a) $(0,1,1)$, or
(b) $(0,1,1)$ and $\left(1_{R}, 0,1\right)$, or
(c) $(0,1,1),\left(1_{R}, 0,1\right)$ and $\left(1_{B}, 1,1\right)$, or
(d) $\left(1_{R}, 0,1\right)$ and $\left(1_{B}, 1,1\right)$. 
Proof: From Lemma A.6, we know that $R_{L}<R_{H}$. From Lemma 4, we know that the only plans that may be chosen by a positive measure of native households are $\left(1_{B}, 1,1\right),\left(1_{R}, 0,1\right),(0,1,1),\left(1_{R}, 0,0\right)$, $(0,0,1)$ and $(0,0,0)$. Because of our assumption that $\nu<S$, there must be a positive measure of native households consuming housing in location 1 in state $H$. This means that at least one of the plans $\left(1_{B}, 1,1\right)$ and $(0,1,1)$ must be chosen. (Here and in what follows, we interpret the word "chosen" to mean "chosen by a positive measure of native households.")

Case 1: $(0,1,1)$ is not chosen, so $\left(1_{B}, 1,1\right)$ must be chosen. We want to show that $\left(1_{R}, 0,1\right),\left(1_{R}, 0,0\right)$ and $(0,0,1)$ are chosen as well. Market clearing requires $D_{1}=D_{L}>D_{H}$, so $\left(1_{R}, 0,1\right)$ must be chosen, or both $\left(1_{R}, 0,0\right)$ and $(0,0,1)$ must be chosen. By part (iv) of Lemma $5,\left(1_{R}, 0,1\right)$ is chosen whenever $\left(1_{R}, 0,0\right)$ is chosen. So $\left(1_{R}, 0,1\right)$ must be chosen. Next, Lemma A.7 implies that $(0,0,0)$ is chosen, so by part (ii) of Lemma 5 , at least one of $(0,0,1)$ and $\left(1_{R}, 0,0\right)$ is chosen. As $D_{1}=D_{L}$, one cannot be chosen without the other.

Case 2: $\left(1_{B}, 1,1\right)$ is not chosen, so $(0,1,1)$ must be chosen. First, note that $\left(1_{R}, 0,0\right)$ must be chosen as well; otherwise, $D_{1}$ cannot equal $D_{L}$. Next, Lemma A.7 implies that $(0,0,0)$ is chosen, so by part (iii) of Lemma $5,(0,0,1)$ is chosen.

Case 3: Both $\left(1_{B}, 1,1\right)$ and $(0,1,1)$ are chosen. Arguing as in the previous case, we see that $\left(1_{R}, 0,0\right)$, $(0,0,1)$ and $(0,0,0)$ are chosen as well. By part (iv) of Lemma 5 , finally, $\left(1_{R}, 0,1\right)$ is also chosen.

Lemma A.9 In an equilibrium where all newcomers choose location 0 in state $H$, the location plans chosen by a positive measure of native households are $(0,0,0),(0,1,1)$, and $(1,0,0)$, plus possibly $(1,1,1)$.

Proof: From Lemma A.6, we know that $R_{L}=R_{H}$. For this case, Lemma A.4 implies that the only housing consumption plans possibly chosen by a positive measure of native households in equilibrium are $(0,0,0),(0,1,1),(1,0,0)$ and $(1,1,1)$. Lemma A.7 implies that $(0,0,0)$ is chosen. Lemma A.5 implies that the configuration cannot just consist of $(0,0,0)$ and $(1,1,1)$. Market clearing implies that if the equilibrium configuration contains $(0,1,1)$, it must also contain $(1,0,0)$, and vice versa.

By Lemma 3, this immediately implies

Lemma A.10 In an equilibrium where all newcomers choose location 0 in state $H$, equation (2) holds with equality; as $R_{L}=R_{H}$, this means $(1+r) R_{1}=R_{L}=R_{H}$.

Lemma A.11 In an equilibrium where a positive measure of newcomers choose location 1 in state $H$, the measure of native households that choose the plan $\left(1_{R}, 0,0\right)$ is at least as large as the measure of native households that choose the plan $(0,1,1)$. As a consequence, $(0,1,1)$ cannot dominate $\left(1_{R}, 0,0\right)$, so (2) holds.

Proof: Suppose to the contrary that fewer native households choose $\left(1_{R}, 0,0\right)$ than $(0,1,1)$. In view of Lemmas A.6 and 4, this implies that $D_{H} \geq D_{L}$, which is incompatible with the premise that a positive measure of newcomers choose location 1 in state $H$.

\section{A.4 Auxiliary results on equilibrium existence and uniqueness}

It will be convenient to work with $e_{1}, e_{L}$, and $e_{H}$ instead of $R_{1}, R_{L}$, and $R_{H}$, respectively. We define $\psi=\mu e^{a W(1-S)}+1$.

Four critical endowment indices fully characterize native households choices. For indifference between $(0,0,0)$ and $(0,0,1)$, the critical endowment index is $i_{1}$ with

$$
\mu e^{a W\left(i_{1}\right)}=\max \left\{\min \left\{e_{L}-1, \mu e^{a W(1)}\right\}, \mu e^{a W(0)}\right\}
$$

For indifference between $(0,0,1)$ and $\left(1_{R}, 0,0\right)$, the critical endowment index is $i_{2}$ with

$$
\mu e^{a W\left(i_{2}\right)}=\max \left\{\min \left\{\frac{e_{1}-\pi-(1-\pi) e_{L}}{\pi}, \mu e^{a W(1)}\right\}, \mu e^{a W(0)}\right\} .
$$


For indifference between $\left(1_{R}, 0,0\right)$ and $\left(1_{R}, 0,1\right)$, the critical endowment index is $i_{3}$ with

$$
\mu e^{a W\left(i_{3}\right)}=\max \left\{\min \left\{e_{1}\left(e_{L}-1\right), \mu e^{a W(1)}\right\}, \mu e^{a W(0)}\right\} .
$$

For indifference between $\left(1_{R}, 0,1\right)$ and $\left(1_{B}, 1,1\right)$, the critical endowment index is $i_{4}$ with

$$
\mu e^{a W\left(i_{4}\right)}=\max \left\{\min \left\{\frac{e_{1}\left(e^{a \bar{R}_{2}}-\pi-(1-\pi) e_{L}\right)}{\pi}, \mu e^{a W(1)}\right\}, \mu e^{a W(0)}\right\} .
$$

Given our results on the set of possible equilibrium configurations, these critical indices satisfy the following conditions in equilibrium: $0<i_{1} \leq i_{2}<i_{3} \leq i_{4}$.

Newcomers face a deterministic one-period problem since they only enter if state $H$ occurs. Given the continuity and monotonicity of the endowment function $\tilde{W}$, we obtain a critical index $n_{1}$ such that the newcomers with index $n>n_{1}$ prefer location 1 over location 0 . This index is implicitly defined by the equation

$$
\mu e^{a \tilde{W}\left(n_{1}\right)}=\max \left\{\min \left\{e_{H}-1, \mu e^{a \tilde{W}(1)}\right\}, \mu e^{a \tilde{W}(0)}\right\} .
$$

Using the definition of the five critical indices, the market clearing conditions for housing in location 1 , period 1 ; period 2, state $H$; and period 2 , state $L$, take the form

$$
\begin{aligned}
S & =1-i_{3}+\rho\left(i_{3}-i_{2}\right), \\
S & =1-i_{4}+(1-\rho)\left(i_{3}-i_{2}\right)+\left(1-n_{1}\right) \nu, \\
S & =1-i_{3}+(1-\rho)\left(i_{3}-i_{2}\right)+i_{2}-i_{1},
\end{aligned}
$$

where $\rho$ is the fraction of households with indices between $i_{2}$ and $i_{3}$ who choose $\left(1_{R}, 0,0\right)$. By definition, $0 \leq \rho \leq 1$. Lemma 3 implies that

$$
(1-\rho)\left(e_{1}-\pi e_{H}-(1-\pi) e_{L}\right)=0 .
$$

Note that our use of min and max operators in the definitions of the critical indices allows us to write each demand for location 1 housing as a single expression for all possible equilibrium configurations.

Lemma A.12 The system of equations (A.26)-(A.29) is equivalent to the system of equations

$$
\begin{aligned}
2(1-S) & =i_{1}+i_{3}, \\
2(1-S)+\nu & =i_{2}+i_{4}+\nu n_{1}, \\
e_{1} & =\pi \min \left\{e_{H}, \mu e^{a W(1-S)}+1\right\}+(1-\pi) e_{L},
\end{aligned}
$$

and

$$
\rho=\frac{i_{3}-(1-S)}{i_{3}-i_{2}}
$$

Proof: Adding equations (A.26) and (A.27), we obtain (A.31). Adding equations (A.26) and (A.28), we obtain (A.30). Now, if $e_{1}<\pi e_{H}+(1-\pi) e_{L}$ then $\rho=1$. Equation (A.26) then implies $i_{2}=1-S$, which by the definition of $i_{2}$ yields

$$
e_{1}=\pi \psi+(1-\pi) e_{L}<\pi e_{H}+(1-\pi) e_{L} .
$$

Then, since $i_{2}=1-S$, equation (A.33) simply becomes $\rho=1$. If $e_{1}=\pi e_{H}+(1-\pi) e_{L}$ then $\rho \leq 1$ and the definition of $i_{2}$ becomes $\mu e^{a W\left(i_{2}\right)}=e_{H}-1$. Moreover, (A.26) implies $i_{2} \leq 1-S$, hence $\mu e^{a W(1-\bar{S})} \geq e_{H}-1$. Therefore:

$$
e_{1}=\pi e_{H}+(1-\pi) e_{L} \leq \pi \psi+(1-\pi) e_{L}
$$


Therefore equation (A.32) holds. Using (A.26), we obtain (A.33).

Conversely, equation (A.32) gives us two possible cases. First, if $\mu e^{a W(1-S)}+1<e_{H}$, then (A.32) plus the definition of $i_{2}$ imply $i_{2}=1-S$, which yields $\rho=1$ by equation (A.33) and implies that equations (A.26) and (A.29) hold. Then, replacing one term $1-S$ by $i_{2}$ in equations (A.31) and (A.30) yields equations (A.27) and (A.28) for the case $\rho=1$. Second, if $\psi \leq e_{H}$, then (A.32) implies that (A.29) holds. Using (A.33) to replace one $1-S$ term in equations (A.31) and (A.30) yields equations (A.27) and (A.28). Rearranging (A.33) yields (A.26).

For our next result, recall the definition of $\underline{e}$ in Section 2.4. It is straightforward to see that $\underline{e}<\psi$.

Lemma A.13 Equations (A.30) and (A.32) yield $e_{1}$ and $e_{L}$ as continuous monotonic functions of $e_{H}$, with the first weakly increasing and the second weakly decreasing in $e_{H}$. The inequality $e_{L}<e_{H}$ holds if and only if $e_{H}>\underline{e}$. More precisely, $\mu e^{a W(1-2 S)}+1<e_{L}<\underline{e}<e_{1}<e_{H}$ if $\underline{e}<e_{H}<\psi$, and $\mu e^{a W(1-2 S)}+1<e_{L}<e_{1}<\psi \leq e_{H}$ if $e_{H} \geq \psi$. Finally, $e_{L}=e_{1}=e_{H}$ if and only if $e_{H}=\underline{e}$.

Proof: Equation (A.30) implies that neither $i_{1}$ nor $i_{3}$ can be zero, and at most one of them can assume the value one. By the definitions of $i_{1}$ and $i_{3}$, the right-hand side of (A.30) is strictly increasing in $e_{L}$, and weakly increasing in $e_{1}$. This defines $e_{L}$ as a weakly decreasing function of $e_{1}$ which assumes the value $\psi$ at $e_{1}=1$ and tends to $\mu e^{a W(1-2 S)}+1$ as $e_{1}$ goes to infinity. Rearranging equation (A.32) into

$$
(1-\pi) e_{L}=e_{1}-\pi \min \left\{e_{H}, \psi\right\}
$$

defines $e_{L}$ as a strictly increasing function of $e_{1}$, given $e_{H}$. This function assumes a value of at most 1 at $e_{1}=1$ and tends to infinity as $e_{1}$ does. This implies that for any given $e_{H}$, (A.30) and (A.32) determine unique values of $e_{1}$ and $e_{L}$ with $\mu e^{a W(1-2 S)}+1<e_{L}<\psi$. An increase in $e_{H}$ either leaves both functions unchanged, or shifts the second function down and leaves the first unchanged. Continuity is obvious.

Next, note that in the $\left(e_{1}, e_{L}\right)$-plane, the graph of the function defined by (A.36) cuts the 45 degree line from below at $e_{1}=\min \left\{e_{H}, \psi\right\}$, while the graph of the function defined by (A.30) cuts the 45 degree line from above at $e_{1}=\underline{e}$. Using these facts, it is now easy to verify the statements about the ranking of $e_{1}, e_{H}$ and $e_{L}$.

Lemma A.14 The system of equations (A.30)-(A.32) has a unique solution with $e_{H} \geq \underline{e}$, and $e_{H}=\underline{e}$ if and only if $\mu e^{a \tilde{W}(1)} \leq \underline{e}-1$.

Proof: We want to to establish that equation (A.31) admits a unique solution $e_{H}$ once $e_{1}$ and $e_{L}$ are solved for as functions of $e_{H}$ according to Lemma A.13. First, we note that $i_{2}$ is weakly increasing in $e_{1}$ and weakly decreasing in $e_{L}$. This implies that $i_{2}$ is weakly increasing in $e_{H}$. Second, $n_{1}$ is also weakly increasing in $e_{H}$. Third, the definition of $i_{4}$ can be rearranged into

$$
\mu e^{a W\left(i_{4}\right)}=\max \left\{\min \left\{e_{1} e_{L}-e_{1}+e_{1} e_{L} z, \mu e^{a W(1)}\right\}, \mu e^{a W(0)}\right\},
$$

where $z=\left[\left(e_{H} / e_{L}\right)^{\pi}-1\right] / \pi$ is strictly increasing in $e_{H}$ and non-negative when $e_{H} \geq \underline{e}$. We know from the proof of Lemma A.13 that $i_{3}>0$. If $i_{3}<1$, then $\mu e^{a W\left(i_{3}\right)}=e_{1} e_{L}-e_{1}$, which is weakly increasing in $e_{H}$ by Lemma A.13 and equation (A.30) because $i_{1}$ is weakly decreasing in $e_{H}$. This in turn implies that $e_{1} e_{L}-e_{1}$ is weakly increasing in $e_{H}$. Given that $e_{1}$ is weakly increasing in $e_{H}, e_{1} e_{L}$ is weakly increasing. So, if $i_{3}<1$, then $i_{4}$ is weakly increasing in $e_{H}$, and strictly increasing up to the level 1 . If $i_{3}=1$, it is immediate that $i_{4}=1$ as well. This establishes that the right-hand side of (A.31) is strictly increasing in $e_{H}$ up to a point and then possibly constant. The term $i_{4}+\nu n_{1}$ becomes constant when $e_{H}$ is so high that $i_{4}=n_{1}=1$. In addition, when $e_{H} \geq \psi$, then equation (A.32) and the definition of $i_{2}$ implies that $i_{2}=1-S$. So, if the right-hand side of (A.31) ever becomes flat as $e_{H}$ increases, it does so at the level $2-S+\nu$ which is greater than the left-hand side of (A.31). At $e_{H}=\underline{e}$, we have $i_{2}=i_{1}$ and $i_{4}=i_{3}$, so (A.30) implies that the right-hand side of (A.31) does not exceed the left-hand side. This establishes existence and uniqueness of a solution to the system of equations (A.30)-(A.32) with $e_{H} \geq \underline{e}$. It also shows that $e_{H}=\underline{e}$ if and only if $n_{1}$ equals 1 at $e_{H}=\underline{e}$, that is, if and only if $\mu e^{a \tilde{W}(1)} \leq \underline{e}-1$. 
Lemma A.15 The solution to the system of equations (A.30)-(A.32) identified in Lemma A.14 constitutes an equilibrium.

Proof: If $\mu e^{a \tilde{W}(1)} \leq \underline{e}-1$, we have $e_{1}=e_{L}=e_{H}=\underline{e}$ by Lemma A.13 and so $0<i_{1}=i_{2}<i_{3}=i_{4}$. If $\mu e^{a \tilde{W}(1)}>\underline{e}-1$, Lemma A.13 implies that $0<i_{1}<i_{2}<i_{3} \leq i_{4}$. This shows that the ranking of the critical endowment indices $i_{1}$ through $i_{4}$ is the one that we assumed when formulating the market clearing conditions (A.26)-(A.29). The solution we have identified thus constitutes an equilibrium.

\section{A.5 Existence and uniqueness of equilibrium in the rental-only economy}

Replicating the arguments we used in the benchmark economy with homeownership, it is easy to verify that in a rental-only equilibrium where some newcomers choose location 1 in state $H$, the rental prices satisfy $R_{L}<R_{H}$ and native households will choose housing consumption plans from the following subset of alternatives: $(0,0,0),(0,0,1),(0,1,1),\left(1_{R}, 0,0\right),\left(1_{R}, 0,1\right)$ and $\left(1_{R}, 1,1\right)$. Again, $(0,1,1)$ is weakly dominated by $\left(1_{R}, 0,0\right)$ and can arise as a native household's equilibrium choice only if (2) holds as an equality. So there are again four critical indices that characterize marginal households. The indices $i_{1}$, $i_{2}, i_{3}$ are defined exactly as in the benchmark economy. For indifference between $\left(1_{R}, 0,1\right)$ and $\left(1_{R}, 1,1\right)$, however, the critical index is now defined by

$$
\mu e^{a W\left(i_{4}\right)}=e^{a(1+r) R_{1}}\left(e^{a R_{H}}-1\right) .
$$

Proposition 2 There is a unique equilibrium in the rental-only economy. If a positive measure of newcomers choose location 1 in state $H$ and a positive measure of native households choose the plan $\left(1_{B}, 1,1\right)$ in the economy where homeownership is allowed, then the equilibrium prices in the rental-only economy compare as follows with those in the ownership economy:

$$
R_{1}^{r} \leq R_{1}^{b}, \quad R_{H}^{r}<R_{H}^{b}, \quad R_{L}^{r} \geq R_{L}^{b} .
$$

Proof of Proposition 2: Existence and uniqueness of equilibrium are shown along exactly the same lines as in the proof of Proposition 1. Note in particular that equations (A.30) and (A.32) are the same in both economies, so Lemma A.13 with its description of $e_{1}$ and $e_{L}$ as continuous monotonic functions of $e_{H}$ carries over without any modification. Given a value for $e_{H}$, we thus have the same values for $e_{1}$, $e_{L}, i_{2}$ and $n_{1}$ in both economies. In contrast, we have $i_{4}^{b}<i_{4}^{r}$ at any given value of $e_{H}$ that is assumed common to both economies, different from $e_{L}$ and such that $0<i_{4}^{b}<1$. By the definitions of these indices, the stated inequality is equivalent to $e_{2}-(1-\pi) e_{L}<\pi e_{H}$, which always holds by the convexity of the exponential function. As a function of $e_{H}$, therefore, the right-hand side of (A.31) is strictly larger in the rental-only economy over the range where $0<i_{4}^{b}<1$. This implies that if $i_{4}^{b}<1$ in the ownership equilibrium, then the equilibrium rental prices in state $H$ satisfy $e_{L}<e_{H}$. The remaining comparison results now follow from Lemma A.13. 